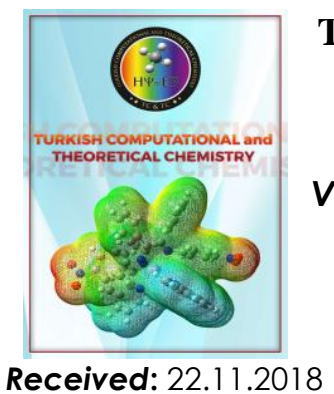

Turkish Computational and Theoretical Chemistry

Turkish Comp Theo Chem (TC\&TC)

Volume(Issue): 3(1) - Year: 2019 - Pages: 25-37

e-ISSN: $2602-3237$

https://doi.org/10.33435/tcandtc. 486573

Accepted: 01.02 .2019

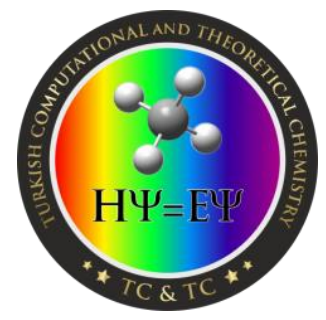

Research Article

\title{
The amidine formed by tacrine and saccharin revisited: An ab initio Investigation of Structural, Electronic and Spectroscopic Properties
}

\author{
Nursel ACAR SELÇUK'̈ ${ }^{l}$
}

Ege University, Faculty of Science, Chemistry Department, 35100 Izmir / Turkey

\begin{abstract}
Computational study of tacrine and saccharin and their amidine complex (TacSac) was peformed by ab initio calculations including electron correlation. Structure, UV-Vis spectra and charge distribution of the amidine (TacSac) were investigated using ground state geometries optimized at MP2/6-311++G(d,p) level. The effects of solvent was investigated using polarizable continuum model (PCM) in conjunction with the solvation model based on density (SMD) approach. TacSac geometry remained same in gas phase and in $\mathrm{H}_{2} \mathrm{O}$ both with PCM and SMD models in contrast to former DFT results. The amidine is calculated to be stable indicating that former DFT calculations underestimated the stability of the investigated amidine. UVVis spectra and electronic transitions were calculated at CIS/6-311++G(d,p), B3LYP/6-311++G(d,p) and CAM-B3LYP/6-311++G(d,p) levels of theory and B3LYP gave the best results. TacSac has a peak at a higher wavelength enabling $\mathrm{S}_{0} \rightarrow \mathrm{S}_{1}$ transition with a lower energy. $\mathrm{S}_{0} \rightarrow \mathrm{S}_{1}$ transition corresponds to full charge transfer between HOMO and LUMO orbitals of TacSac in $\mathrm{H}_{2} \mathrm{O}$. The ab initio results indicate that the TacSac system can be synthesized with an easy condensation reaction, and that the amidine product is a potential candidate for photochemical charge-transfer systems.
\end{abstract}

\section{Keywords: Amidine, Møller-Plesset, Density Functional Theory, Tacrine, Saccharin}

\section{Introduction}

Interactions of molecules under physiological conditions are of great interest as they can be directly involved in human metabolism. Especially, drugs and nutrient components receive a special interest as they play critical roles in human daily life.

One of these compounds is tacrine $(1,2,3,4$ tetrahydroacridin-9-amine, Fig. 1) which was first synthesized towards the end of World War II [1]. It was among the 90 acridine derivatives obtained for wound treatment [2,3]. After the war, studies revealed that tacrine was an effective acetylcholinesterase (AChE) inhibitor and could be used for Alzheimer's disease (AD). Tacrine crosses the blood-brain barrier easily and effectively inhibits central AChE [4]. Its tricyclic structure is

\footnotetext{
${ }^{1}$ Corresponding Author

e-mail: nursel.acar@ege.edu.tr
}

the major factor in AChE inhibition [5]. Its use for AD started in 1984, and its results was first reported in 1986 [6]. It is the first drug for AD treatment receiving FDA approval [7]. As determined by crystallographic studies, tacrine binds directly and selectively to the active site of AchE without interacting with any other site [8]. Since tacrine displays unusual interaction properties, many computational studies were also reported on tacrine [9-11].
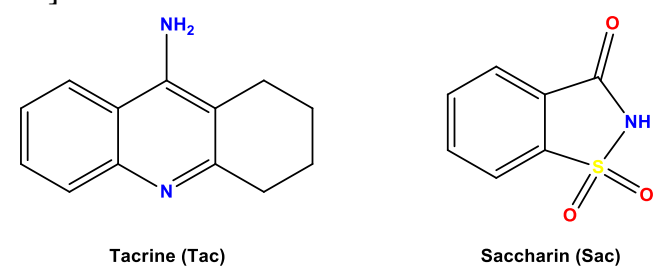

Fig. 1. 2D representation of tacrine (Tac) and saccharin (Sac) molecules 
Another such molecule is saccharin (1,2benzisothiazol-3(2H)-one-1,1-dioxide, Fig. 1), a commercial artificial sweetener [12]. Artificial sweeteners, including saccharin, are sugar replacements for many diseases like diabetes and obesity. However, use of these substitutes can result in severe health problems including bladder cancer, heart failure, and brain tumors as well as psychological and mental disorders [13-18]. Recently, many producers started to replace saccharin with alternative sweeteners due to speculations on its carcinogenic effects [12]. Although most of the studies on saccharin are experimental, molecular modeling studies were also reported on saccharin and its anion [12, 1922].

Amidines have amide and imine functional groups and are referred as nitrogen analogues of carboxylic acids [23]. An amino group replaces the hydroxyl moiety and an azomethine double bond replaces the carbonyl group. Structurally, they are carboxylic acid imidates $[24,25]$ and their $\mathrm{pK}_{\mathrm{a}}$ values are within the range of 5-12 [26].

If they are protonated, they behave as strong organic bases caused by the charge delocalization on two nitrogens. The amidine structure also attract attention as it can establish specific interactions with proteins mainly through bidentate hydrogen bonds, and the amidino group can modulate this recognition process [27]. In the literature, many bioactive amidine based inhibitors are reported for three enzyme families: the NOS, the dimethylarginine dimethylaminohydrolase (DDAH) and the peptidylarginine deiminase (PAD) [28].

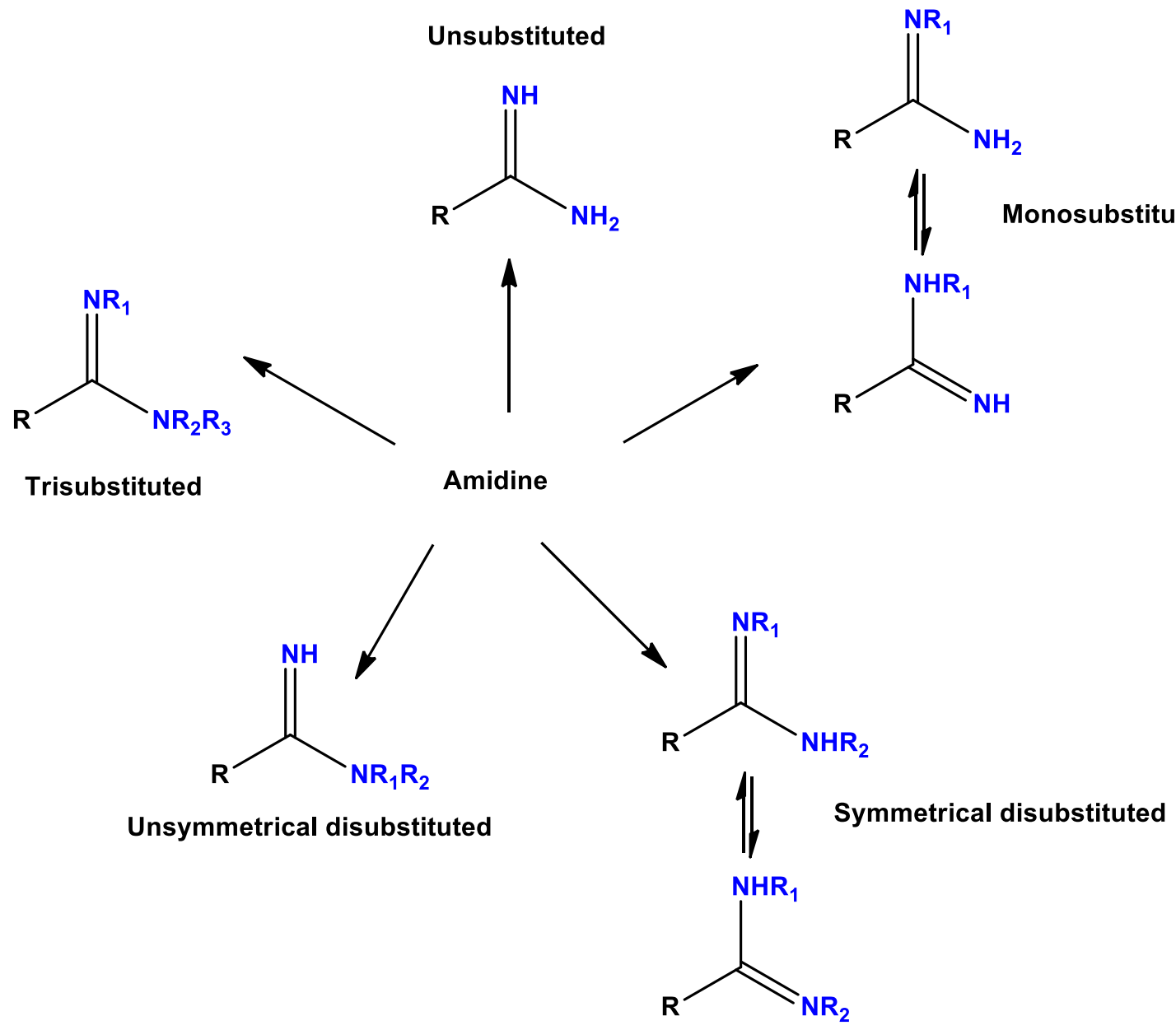

Fig. 2. Five amidine classes described by Shriner and Neumann [29]. 
A general classification of amidines is given by Shriner and Neumann depending on the susbstitution characteristics of nitrogen atoms: (i) unsubstituted, (ii) monosubstituted, (iii) symmetrical disubstituted, (iv) unsymmetrical disubstituted, (v) trisubstituted [29]. General structure of these amidine types are displayed in Fig. 2.

Major components of DNA, the nucleobases are also amidines [30]. They are used in organic synthesis [31], and attract attention for their unique properties like prototropy [30] and superbasicity [32]. Amidine derivatives are also used as antiparasitics [33], antitumor drugs [34], purification agents [35], nucleophilic catalysts [36], fungicides [37], and polymeric adhesives [38]. A recent study revealed that amidine conjugation may also play a significant role on electronic structures by stabilizing unstable intermediates and enabling researchers to isolate these compounds [39]. Some additional properties are reported in a recent review [40].
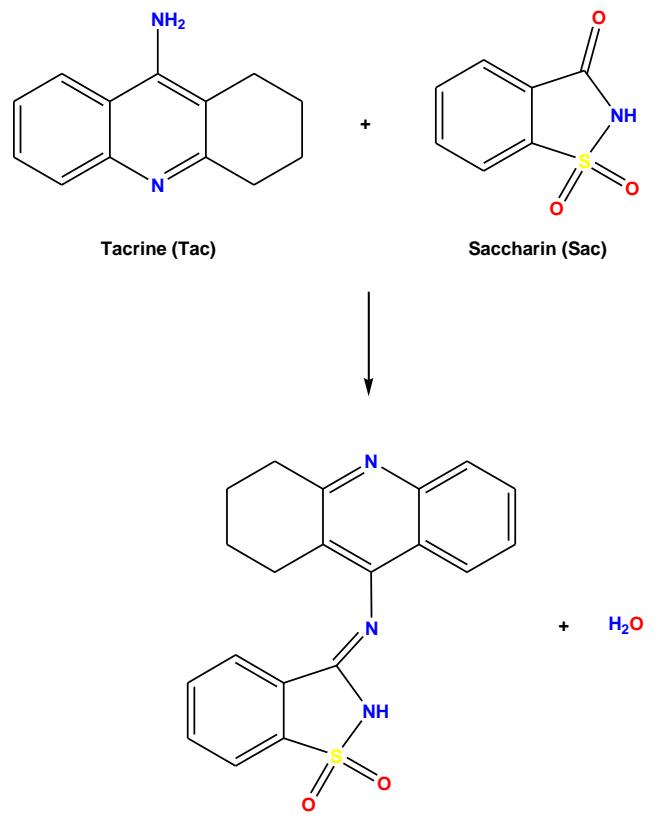

Tacrine-Saccharin Complex (TacSac, Amidine)

Fig. 3. Schematic representation for the formation reaction of Tacrine-Saccharin complex (TacSac)

There are many studies reported on tacrine and saccharin; but, neither experimental nor computational studies are reported on the tacrinesaccharin complex formed by the reaction of tacrine and saccharin to form an amidine (TacSac, Fig. 3) except our recent computational study [41]. We investigated the spectroscopic properties of TacSac using density functional theory (DFT) and timedependent density functional theory (TDDFT) with different functionals. The computational spectra were in good aggreement with experimental results but there were some discrepancies about the structures with different solvent approaches. In current study, it is our aim to clarify those dicrepancies by repeating the calculations at a higher ab initio level including electron correlation.

\section{Computational Method}

The initial geometries obtained from the conformational research in our previous work [41] were used for Tac, Sac and TacSac. The structures of investigated systems were visualized by Gaussview 5.0.9 [42]. Geometry optimizations and frequency calculations were performed with Gaussian 09 Revision-C.01 [43]. Second order Møller-Plesset perturbation (MP2) method [44, 45] was used to optimize all possible conformers of the investigated structures in both media. Pople type 6$311++\mathrm{G}(\mathrm{d}, \mathrm{p})$ basis set was used in all calculations [46]. Frequency calculations followed geometry optimizations and all calculated frequencies were positive. The most stable conformer for each system was used in further calculations.

To obtain the computational UV-Vis spectra, excited state calculations on ground state structures were carried out with CIS method [47] and TimeDependent Density Functional Theory (TDDFT) using B3LYP (Becke-style three-parameter functional with Lee-Yang-Parr exchangecorrelation) [48, 49] and CAM-B3LYP (Coulombattenuating method for B3LYP) [50] functionals using the same basis set. The latter includes long range corrections to B3LYP method. For each investigated system, the first 100 singlet excited states were taken into account.

The polarizable continuum model (PCM) $[51,52]$ was used with default options in Gaussian 09 to evaluate the solvent effect. Calculations were repeated with the SMD (solvation model based on density) approximation [53] to observe the contributions of nonelectrostatic solute-solvent interactions. Atomic Polar Tensor (APT) approach was used for charge analysis [54]. 
Turkish Comp Theo Chem (TC\&TC), 3(1), (2019), 25 - 37

\section{Nursel ACAR SELÇUKI}

\section{Results and discussion}

The results are discussed in three sections. The first part reports the calculated geometries and energies of investigated systems in gas phase and in solution. Second part focuses on UV-Vis spectra and electronic transitions and the third part summarizes the results on charge analysis.

Table 1. Optimized geometries and some selected structural parameters for the investigated systems in gas phase and in solution at MP2/6-311++G(d,p)

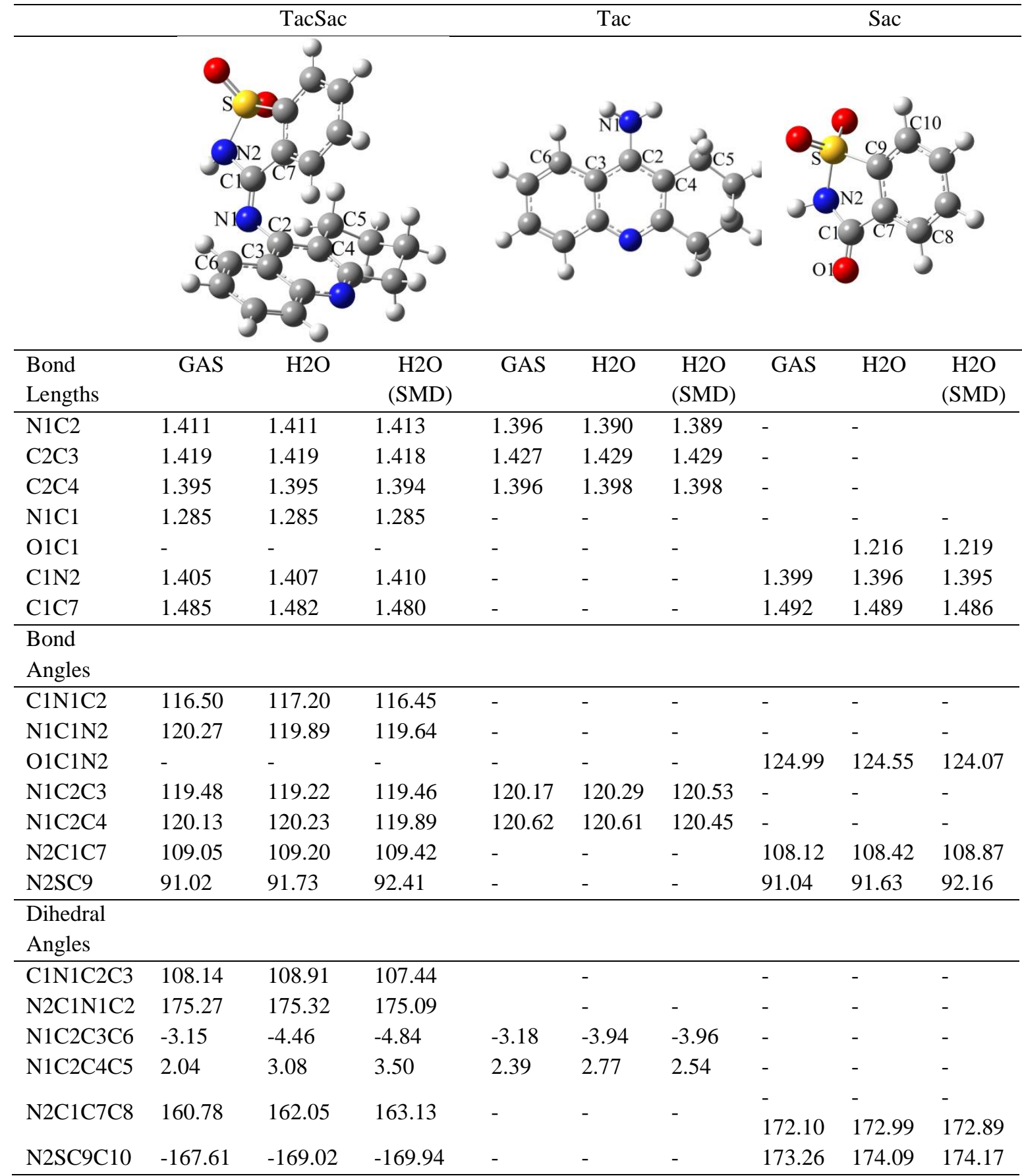

\subsection{Optimized Structures}

MP2/6-311++G(d,p) level was used to investigate the structures of Tacrine (Tac), Saccharin (Sac) and their complex (TacSac). The optimized structures and some selected structural parameters are given in Table 1. A simplified numbering system is used to follow the parameters easily and may vary for each studied system. 
As seen from Table 1, there are no significant changes in the geometries of investigated systems in different media. However, the geometry of TacSac presents significant differences compared to its parent compounds Tac and Sac. The N1C2 $(\sim 0.015 \AA)$ and $\mathrm{C} 1 \mathrm{~N} 2(\sim 0.010 \AA)$ bond lengths increased in contrast to $\mathrm{C} 2 \mathrm{C} 3(\sim 0.010 \AA)$ and $\mathrm{C} 1 \mathrm{C} 7$ $\left(\begin{array}{ll}\sim 0.010 & \AA\end{array}\right)$ which decreased in TacSac. Interestingly, $\mathrm{C} 2 \mathrm{C} 4$ bond length change is negligible. This may be explained by the fact that $\mathrm{C} 2 \mathrm{C} 4$ bond lies on the aliphatic side of the Tac and affected least by the changes in the resonance structure of the aromatic moiety. Similar changes are observed for bond angles, too. $\mathrm{N} 1 \mathrm{C} 2 \mathrm{C} 3$ decreases approximately $1^{\circ}$ compared to Tac whereas $\mathrm{N} 2 \mathrm{C} 1 \mathrm{C} 7$ increases by the same amount compared to Sac. N1C2C4 and N2SC9 are almost identical without any significant changes. The most significant changes are observed for dihedral angles as expected. After the two cyclic molecules are covalently bonded through $\mathrm{C}-\mathrm{N}$ double bond, steric repulsions occur due to the close contacts between two cyclic systems. As seen by the changes for N1C2C3C6, N1C2C4C5, N2C1C7C8 and $\mathrm{N} 2 \mathrm{SC} 9 \mathrm{C} 10$ dihedrals, both cyclic molecules are distorted from their initial geometries in TacSac due to steric repulsions. The deviations are larger with respect to Sac which go up to $10^{\circ}$ whereas it is much smaller (around $1^{\circ}$ ) compared to Tac.

The results revealed that the geometry is only slightly affected by the presence of a polar solvent $\left(\mathrm{H}_{2} \mathrm{O}\right)$. Since the IEF-PCM model is an implicit model, it only calculates the electrostatic interactions and it is not possible to investigate specific interactions (i.e. hydrogen bonding) between solute and solvent molecules. Interestingly, inclusion of nonelectrostatic terms to IEF-PCM by SMD approach does not show any significant changes in the geometries in contrast to our former results [41]. It may be concluded that steric factors dominate over all other possible factors effecting geometries for the investigated systems.

Table 2. Calculated total electronic energies with zero-point energy corrections ( $\mathrm{E}_{\mathrm{TOT}}(\mathrm{ZPE})$, Hartree), dipole moments ( $\mu$, Debye), sum of total electronic energy, ZPE and Gibbs free energy ( $\Delta \mathrm{G}$, Hartree), complexation energies $\left(E_{C}, \mathrm{kcal} / \mathrm{mol}\right)$ and changes in Gibbs free energy $(\Delta \Delta \mathrm{G}, \mathrm{kcal} / \mathrm{mol})$ for the investigated systems calculated at MP2/6-311++G(d,p) in gas phase and in solution $\left(\right.$ in $\left.\mathrm{H}_{2} \mathrm{O}\right)$.

\begin{tabular}{lccccc}
\hline Gas & $\begin{array}{c}\text { Eтот }(\mathbf{Z P E}) \\
(\text { Hartree) }\end{array}$ & $\begin{array}{c}\mu \\
\text { (Debye) }\end{array}$ & $\begin{array}{c}\Delta \mathbf{G} \\
\text { (Hartree) }\end{array}$ & $\begin{array}{c}\mathbf{E c}_{\mathbf{c}}^{\mathbf{a}} \\
(\mathbf{k c a l} / \mathbf{m o l})\end{array}$ & $\begin{array}{c}\Delta \Delta \mathbf{G}^{\mathbf{b}} \\
(\mathbf{k c a l} / \mathbf{m o l})\end{array}$ \\
\hline Tacrine & -611.4375992 & 3.30 & -611.4751130 & $\mathbf{- 5 . 0 5}$ & $\mathbf{- 1 . 8 4}$ \\
Saccharin & -946.3721482 & 5.15 & -946.4074900 & & \\
TacSac & -1481.5645700 & 4.19 & -1481.6146770 & & \\
H2O & -76.2532253 & 2.26 & -76.2708660 & &
\end{tabular}

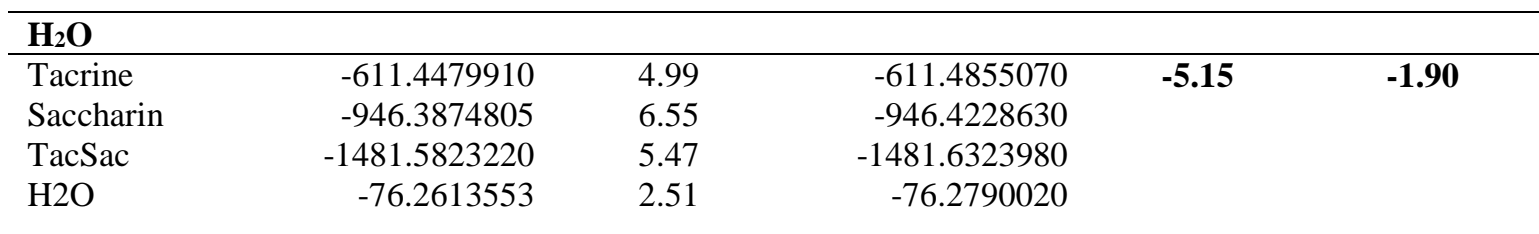

\begin{tabular}{|c|c|c|c|c|c|}
\hline \multicolumn{6}{|c|}{$\mathrm{H}_{2} \mathrm{O}$ (SMD) } \\
\hline Tacrine & -611.4532624 & 5.51 & -611.4908310 & -8.62 & -5.42 \\
\hline Saccharin & -946.3926688 & 7.23 & -946.4279150 & & \\
\hline TacSac & -1481.5925607 & 6.01 & -1481.6426200 & & \\
\hline $\mathrm{H} 2 \mathrm{O}$ & -76.2671048 & 2.72 & -76.2847570 & & \\
\hline
\end{tabular}

${ }^{\mathrm{a}} \Delta \mathrm{E}_{\mathrm{C}}=\left(\mathrm{E}_{\mathrm{TacSac}}+\mathrm{E}_{\mathrm{H} 2 \mathrm{O}}\right)-\left(\mathrm{E}_{\mathrm{Tac}}+\mathrm{E}_{\mathrm{Sac}}\right)$

${ }^{\mathrm{b}} \Delta \Delta \mathrm{G}=\left(\Delta \mathrm{G}_{\mathrm{TacSac}}+\Delta \mathrm{G}_{\mathrm{H} 2 \mathrm{O}}\right)-\left(\Delta \mathrm{G}_{\mathrm{Tac}}+\Delta \mathrm{G}_{\mathrm{Sac}}\right)$ 


\section{Nursel ACAR SELÇUKI}

Table 2 summarizes some calculated properties including total electronic energies, Gibbs free energy differences and dipole moments according to the reaction given in Fig. 3. In our former DFT study [41], our results indicate that formation of the TacSac complex requires energy $\left(\mathrm{E}_{\mathrm{C}}\right.$ values vary between +5 to $+12 \mathrm{kcal} / \mathrm{mol}$ ) and is a nonspontaneous endergonic process with $\Delta \Delta \mathrm{G}$ values around $+10 \mathrm{kcal} / \mathrm{mol}$. However, in current study, MP2 results revealed a quite oppposite tendency. As seen in Table 2, formation of TacSac is a spontaneous exergonic process in all media with negative $\Delta \Delta G$ values and $E_{C}$ values vary between -5 to $8 \mathrm{kcal} / \mathrm{mol}$. Depending on new MP2 results, it may be concluded that the formation reaction for TacSac is much easier than formerly predicted. Another important outcome from Table 2 is the energy values calculated with SMD approximation. Although nonelectrostatic interactions do not play major roles in geometries of investigated systems, their contributions to the electronic and free energies are significant. By inclusion of SMD terms both $\mathrm{E}_{\mathrm{C}}$ and $\Delta \Delta \mathrm{G}$ values become more negative by approximately 3.50 $\mathrm{kcal} / \mathrm{mol}$. This observation is similar to our former DFT results.

\subsection{UV-Vis Spectra and Electronic Transitions}

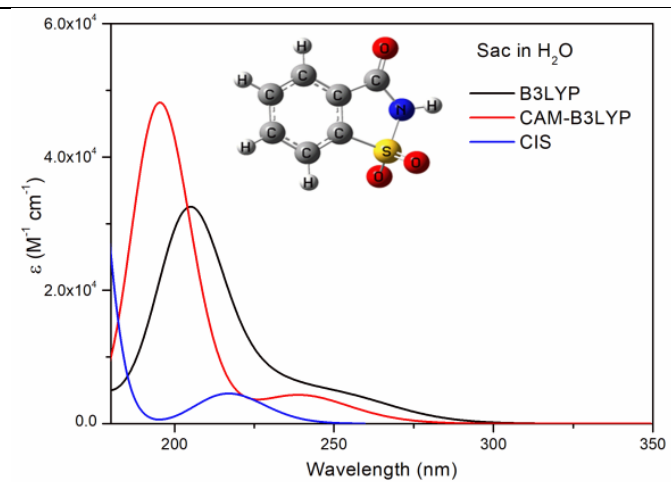

b

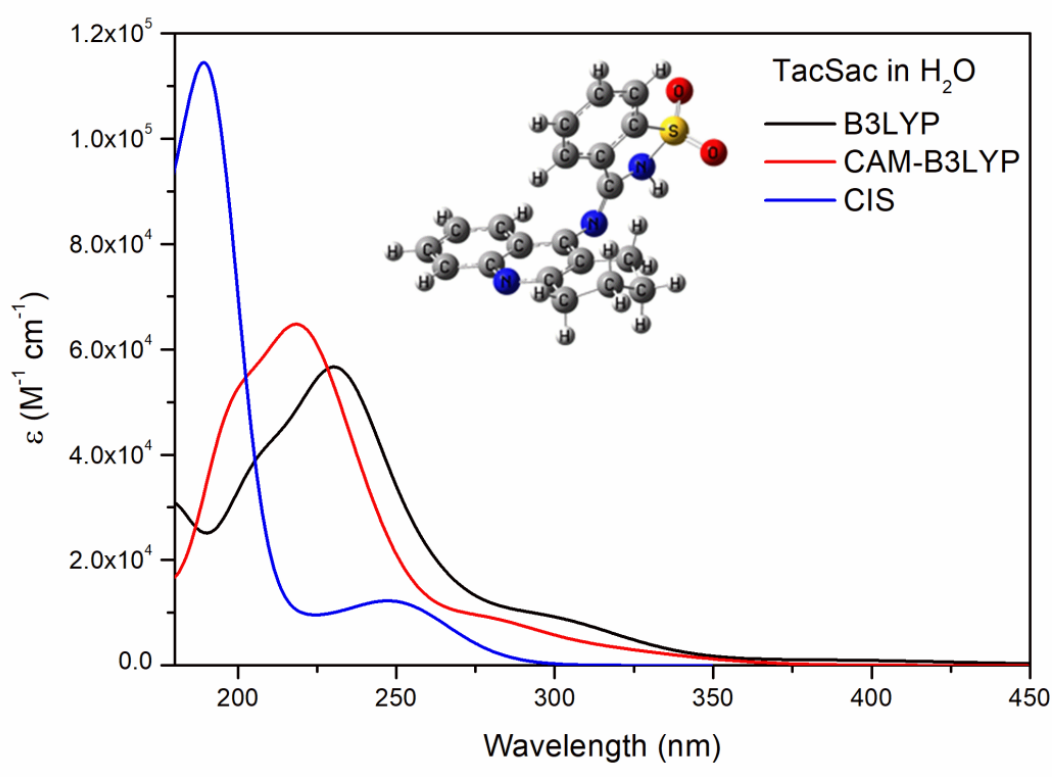

c

Fig. 4. Calculated UV-Vis spectra of a) Tac, b) Sac and, c) TacSac in $\mathrm{H}_{2} \mathrm{O}$ with different methods using 6-311++G(d,p) basis set 
In our previous study, we performed TD-DFT calculations to obtain UV-Vis spectra with different functionals on ground state geometries obtained at B3LYP/6-311++G(d,p) level using the first 40 singlet states [41]. The experimental and computational results were in good agreement but because of the discrepancies in the optimized TacSac geometries, the calculations were repeated with ground state geometries obtained at MP2/6$311++G(d, p)$ level. In order to compare results, the CIS method and B3LYP and CAM-B3LYP functionals together with $6-311++G(d, p)$ basis set were used to obtain first 100 singlet states.

Fig. 4 displays the calculated UV-Vis spectra of investigated compounds in $\mathrm{H}_{2} \mathrm{O}$ with different methods. Comparison of the UV-Vis spectra with available experimental data reported in [41], B3LYP/6-311++G(d,p) level is determined to have the best correlation to the experimental results. The following discussion is based on B3LYP/6$311++\mathrm{G}(\mathrm{d}, \mathrm{p})$ results unless otherwise stated.

Electronic transitions and related properties calculated at B3LYP/6-311++G(d,p) level for Tac, Sac and TacSac are given in Tables 3, 4 and 5, respectively. As seen in Table 3 and Fig 4, Tac has a peak at $312 \mathrm{~nm}$. This peak corresponds to local excitation of Tac (LE1) at $\mathrm{S}_{1}$ transition. There is also an intramolecular charge transfer (ICT) from $\mathrm{NH}_{2}$ substituent towards the ring system of Tac observed at $247 \mathrm{~nm}$ with an $\mathrm{n} \rightarrow \pi^{*}$ transition character. This transition is also observed at $289 \mathrm{~nm}$ from $\mathrm{H} \rightarrow \mathrm{L}+1$ with a very small oscillator strength. The molecular orbitals contributing to the electronic transitions observed for Tac, Sac and TacSac are given in Fig. S1.

Sac has a peak at $273 \mathrm{~nm}$ (Fig 4, Table 4) which corresponds to its local excitation (LE2). This observation is also supported by the results calculated for TacSac in the further discussion.

Table 3. Electronic transitions $\left(\lambda_{\mathrm{ex}}\right)$ correlated to vertical excitation energies $(\Delta \mathrm{E})$, transition dipole moments $\left(\mu_{\mathrm{tr}}\right)$, oscillator strengths (f), excitation character, molecular orbitals with their $\%$ contributions in water calculated at B3LYP/6-311++G(d,p) level for Tac

\begin{tabular}{|c|c|c|c|c|c|c|c|}
\hline state & $\begin{array}{c}\Delta \mathrm{E} \\
(\mathrm{eV})\end{array}$ & $\begin{array}{c}\lambda_{\mathrm{ex}} \\
(\mathrm{nm})\end{array}$ & $\begin{array}{l}\mu_{\mathrm{tr}} \\
(\mathrm{D})\end{array}$ & $\mathrm{f}$ & Character $^{\mathrm{a}}$ & $\begin{array}{l}\text { Predominant } \\
\text { Transitions }\end{array}$ & $\%$ \\
\hline $\mathrm{S}_{1}$ & 3.97 & 311.6 & 1.1441 & 0.1115 & LE1 & $\mathrm{H} \rightarrow \mathrm{L}$ & 69 \\
\hline $\mathrm{S}_{2}$ & 4.29 & 288.9 & 0.0365 & 0.0038 & $\begin{array}{l}\text { ICT,LE1 } \\
\text { ICT,LE1 }\end{array}$ & $\begin{array}{l}\mathrm{H}-1 \rightarrow \mathrm{L} \\
\mathrm{H} \rightarrow \mathrm{L}+1\end{array}$ & $\begin{array}{l}50 \\
49\end{array}$ \\
\hline $\mathrm{S}_{3}$ & 4.56 & 271.6 & 0.0125 & 0.0014 & LE1 & $\mathrm{H}-2 \rightarrow \mathrm{L}$ & 69 \\
\hline $\mathrm{S}_{4}$ & 5.01 & 247.3 & 0.4847 & 0.0595 & ICT & $\mathrm{H} \rightarrow \mathrm{L}+2$ & 66 \\
\hline $\mathrm{S}_{5}$ & 5.14 & 241.0 & 1.8928 & 0.2385 & $\begin{array}{c}\text { LE1 } \\
\text { ICT,LE1 }\end{array}$ & $\begin{array}{l}\mathrm{H}-3 \rightarrow \mathrm{L} \\
\mathrm{H}-1 \rightarrow \mathrm{L}\end{array}$ & $\begin{array}{l}51 \\
29\end{array}$ \\
\hline $\mathrm{S}_{6}$ & 5.17 & 239.7 & 5.4946 & 0.6964 & $\begin{array}{l}\text { ICT,LE1 } \\
\text { LE1 } \\
\text { ICT,LE1 }\end{array}$ & $\begin{array}{l}\mathrm{H} \rightarrow \mathrm{L}+1 \\
\mathrm{H}-3 \rightarrow \mathrm{L} \\
\mathrm{H}-1 \rightarrow \mathrm{L}\end{array}$ & $\begin{array}{l}39 \\
36 \\
34\end{array}$ \\
\hline $\mathrm{S}_{7}$ & 5.38 & 230.3 & 0.2568 & 0.0339 & ICT,LE1 & $\mathrm{H}-2 \rightarrow \mathrm{L}+1$ & 68 \\
\hline $\mathrm{S}_{8}$ & 5.46 & 227.2 & 0.0668 & 0.0089 & $\begin{array}{l}\text { ICT } \\
\text { ICT }\end{array}$ & $\begin{array}{l}\mathrm{H} \rightarrow \mathrm{L}+3 \\
\mathrm{H} \rightarrow \mathrm{L}+4\end{array}$ & $\begin{array}{l}53 \\
44\end{array}$ \\
\hline $\mathrm{S}_{9}$ & 5.48 & 226.1 & 0.1729 & 0.0232 & $\begin{array}{l}\text { LE1 } \\
\text { ICT }\end{array}$ & $\begin{array}{l}\mathrm{H} \rightarrow \mathrm{L}+4 \\
\mathrm{H} \rightarrow \mathrm{L}+3\end{array}$ & $\begin{array}{l}51 \\
43\end{array}$ \\
\hline $\mathrm{S}_{10}$ & 5.61 & 221.1 & 0.0568 & 0.0078 & LE1 & $\mathrm{H} \rightarrow \mathrm{L}+5$ & 62 \\
\hline$S_{11}$ & 5.76 & 215.4 & 1.4070 & 0.1985 & ICT,LE1 & $\mathrm{H}-1 \rightarrow \mathrm{L}+1$ & 58 \\
\hline
\end{tabular}

${ }^{\mathrm{a}} \mathrm{LE} 1$ = local excitation of tacrine; ICT $=$ intramolecular charge-transfer 
Turkish Comp Theo Chem (TC\&TC), 3(1), (2019), 25 - 37

Nursel ACAR SELÇUKI

Table 4. Electronic transitions $\left(\lambda_{\mathrm{ex}}\right)$ corresponding to vertical excitation energies $(\Delta \mathrm{E})$, transition dipole moments $\left(\mu_{\mathrm{tr}}\right)$, oscillator strengths (f), excitation character, molecular orbitals and their $\%$ contributions in water calculated at B3LYP/6-311++G(d,p) level for Sac

\begin{tabular}{|c|c|c|c|c|c|c|c|}
\hline State & $\Delta \mathrm{E}(\mathrm{eV})$ & $\lambda_{\text {ex }}(\mathrm{nm})$ & $\mu_{\mathrm{tr}}(\mathrm{D})$ & $\mathrm{f}$ & Character $^{\mathrm{a}}$ & $\begin{array}{c}\text { Predominant } \\
\text { Transitions }\end{array}$ & $\%$ \\
\hline $\mathrm{S}_{1}$ & 4.54 & 273.0 & 0.0162 & 0.0018 & LE2 & $\mathrm{H}-2 \rightarrow \mathrm{L}$ & 65 \\
\hline $\mathrm{S}_{2}$ & 4.74 & 261.7 & 0.2580 & 0.0299 & $\begin{array}{l}\text { ICT,LE2 } \\
\text { LE2 }\end{array}$ & $\begin{array}{l}\mathrm{H} \rightarrow \mathrm{L} \\
\mathrm{H}-1 \rightarrow \mathrm{L}\end{array}$ & $\begin{array}{l}58 \\
27\end{array}$ \\
\hline $\mathrm{S}_{3}$ & 4.94 & 250.9 & 0.5353 & 0.0648 & $\begin{array}{c}\text { LE2 } \\
\text { ICT,LE2 }\end{array}$ & $\mathrm{H}-1 \rightarrow \mathrm{L} \mathrm{H} \rightarrow \mathrm{L}$ & $\begin{array}{l}52 \\
30\end{array}$ \\
\hline $\mathrm{S}_{4}$ & 5.40 & 229.8 & 0.9073 & 0.1200 & $\begin{array}{l}\text { ICT2 } \\
\text { LE2 }\end{array}$ & $\begin{array}{l}\mathrm{H}-3 \rightarrow \mathrm{L} \\
\mathrm{H}-2 \rightarrow \mathrm{L}\end{array}$ & $\begin{array}{l}60 \\
23\end{array}$ \\
\hline $\mathrm{S}_{5}$ & 5.82 & 212.9 & 0.1859 & 0.0265 & ICT2,LE2 & $\mathrm{H}-2 \rightarrow \mathrm{L}+1$ & 64 \\
\hline $\mathrm{S}_{6}$ & 5.97 & 207.5 & 3.0939 & 0.4528 & $\begin{array}{c}\text { ICT2 } \\
\text { LE2 }\end{array}$ & $\begin{array}{l}\mathrm{H}-1 \rightarrow \mathrm{L}+1 \\
\mathrm{H} \rightarrow \mathrm{L}+1\end{array}$ & $\begin{array}{l}41 \\
34\end{array}$ \\
\hline $\mathrm{S}_{7}$ & 6.03 & 205.5 & 0.0779 & 0.0115 & LE2 & $\mathrm{H}-4 \rightarrow \mathrm{L}$ & 67 \\
\hline $\mathrm{S}_{8}$ & 6.07 & 204.2 & 0.0761 & 0.0113 & ICT2 & $\mathrm{H}-3 \rightarrow \mathrm{L}+1$ & 65 \\
\hline $\mathrm{S}_{9}$ & 6.15 & 201.4 & 2.1235 & 0.3203 & $\begin{array}{c}\text { LE2 } \\
\text { ICT2 }\end{array}$ & $\begin{array}{l}\mathrm{H} \rightarrow \mathrm{L}+1 \\
\mathrm{H}-1 \rightarrow \mathrm{L}+1\end{array}$ & $\begin{array}{l}51 \\
36\end{array}$ \\
\hline
\end{tabular}

${ }^{\mathrm{a}} \mathrm{LE} 2$ = local excitation of saccharin; ICT $=$ intramolecular charge-transfer

Table 5. Electronic transitions $\left(\lambda_{\mathrm{ex}}\right)$ correlated to vertical excitation energies $(\Delta \mathrm{E})$, transition dipole moments $\left(\mu_{\mathrm{tr}}\right)$, oscillator strengths (f), excitation character, molecular orbitals and their \% contributions in water calculated at B3LYP/6-311++G(d,p) level for TacSac

\begin{tabular}{|c|c|c|c|c|c|c|c|}
\hline state & $\Delta \mathrm{E}(\mathrm{eV})$ & $\lambda_{\text {ex }}(\mathrm{nm})$ & $\mu_{\mathrm{tr}}(\mathrm{D})$ & $\mathrm{f}$ & Character $^{\mathrm{a}}$ & $\begin{array}{c}\text { Predominant } \\
\text { Transitions }\end{array}$ & $\%$ \\
\hline $\mathrm{S}_{1}$ & 3.16 & 391.6 & 0.2934 & 0.0228 & CT1 & $\mathrm{H} \rightarrow \mathrm{L}$ & 69 \\
\hline $\mathrm{S}_{2}$ & 3.80 & 325.9 & 0.2010 & 0.0187 & CT1 & $\mathrm{H}-1 \rightarrow \mathrm{L}$ & 70 \\
\hline $\mathrm{S}_{3}$ & 4.08 & 303.7 & 0.7556 & 0.0756 & $\begin{array}{c}\text { CT1 } \\
\text { LE1,CT1 }\end{array}$ & $\begin{array}{l}\mathrm{H} \rightarrow \mathrm{L}+2 \\
\mathrm{H} \rightarrow \mathrm{L}+1\end{array}$ & $\begin{array}{l}55 \\
40\end{array}$ \\
\hline $\mathrm{S}_{4}$ & 4.11 & 301.7 & 0.5359 & 0.0540 & $\begin{array}{c}\text { LE1,CT } \\
\text { CT1 }\end{array}$ & $\begin{array}{l}\mathrm{H} \rightarrow \mathrm{L}+1 \\
\mathrm{H} \rightarrow \mathrm{L}+2\end{array}$ & $\begin{array}{l}50 \\
37\end{array}$ \\
\hline $\mathrm{S}_{5}$ & 4.14 & 299.8 & 0.1309 & 0.0133 & $\begin{array}{c}\text { CT1 } \\
\text { LE1,CT1 }\end{array}$ & $\begin{array}{l}\mathrm{H}-2 \rightarrow \mathrm{L} \\
\mathrm{H} \rightarrow \mathrm{L}+1\end{array}$ & $\begin{array}{l}61 \\
22\end{array}$ \\
\hline $\mathrm{S}_{6}$ & 4.35 & 285.1 & 0.4522 & 0.0482 & $\begin{array}{l}\text { LE1,CT1 } \\
\text { LE1 }\end{array}$ & $\begin{array}{l}\mathrm{H}-1 \rightarrow \mathrm{L}+1 \\
\mathrm{H} \rightarrow \mathrm{L}+3\end{array}$ & $\begin{array}{l}52 \\
38\end{array}$ \\
\hline $\mathrm{S}_{7}$ & 4.40 & 281.6 & 0.2739 & 0.0296 & $\begin{array}{l}\text { LE2,CT1 } \\
\text { LE2,CT1 }\end{array}$ & $\begin{array}{l}\mathrm{H}-3 \rightarrow \mathrm{L} \\
\mathrm{H}-4 \rightarrow \mathrm{L}\end{array}$ & $\begin{array}{l}55 \\
27\end{array}$ \\
\hline $\mathrm{S}_{8}$ & 4.58 & 270.7 & 0.1397 & 0.0157 & $\begin{array}{l}\text { LE1,CT1 } \\
\text { CT1 }\end{array}$ & $\begin{array}{l}\mathrm{H}-2 \rightarrow \mathrm{L}+1 \\
\mathrm{H}-2 \rightarrow \mathrm{L}\end{array}$ & $\begin{array}{l}60 \\
24\end{array}$ \\
\hline $\mathrm{S}_{9}$ & 4.69 & 264.1 & 0.1391 & 0.0160 & $\begin{array}{l}\text { CT1 } \\
\text { LE2 }\end{array}$ & $\begin{array}{l}\mathrm{H}-1 \rightarrow \mathrm{L}+2 \\
\mathrm{H}-5 \rightarrow \mathrm{L}\end{array}$ & $\begin{array}{l}42 \\
41\end{array}$ \\
\hline$S_{10}$ & 4.70 & 263.7 & 0.1911 & 0.0220 & $\begin{array}{l}\text { CT1 } \\
\text { LE2 }\end{array}$ & $\begin{array}{l}\mathrm{H}-1 \rightarrow \mathrm{L}+2 \\
\mathrm{H}-5 \rightarrow \mathrm{L}\end{array}$ & $\begin{array}{l}56 \\
34\end{array}$ \\
\hline$S_{11}$ & 4.83 & 256.4 & 1.9934 & 0.2361 & $\begin{array}{l}\text { LE2,CT1 } \\
\text { LE2 }\end{array}$ & $\begin{array}{l}\mathrm{H}-4 \rightarrow \mathrm{L} \\
\mathrm{H}-5 \rightarrow \mathrm{L}\end{array}$ & $\begin{array}{l}48 \\
29\end{array}$ \\
\hline $\mathrm{S}_{12}$ & 4.94 & 250.9 & 0.4617 & 0.0559 & LE2 & $\mathrm{H}-6 \rightarrow \mathrm{L}$ & 63 \\
\hline
\end{tabular}

aLE1 = local excitation of tacrine; LE2 = local excitation of saccharin; CT1 = charge-transfer from tacrine to saccharin 


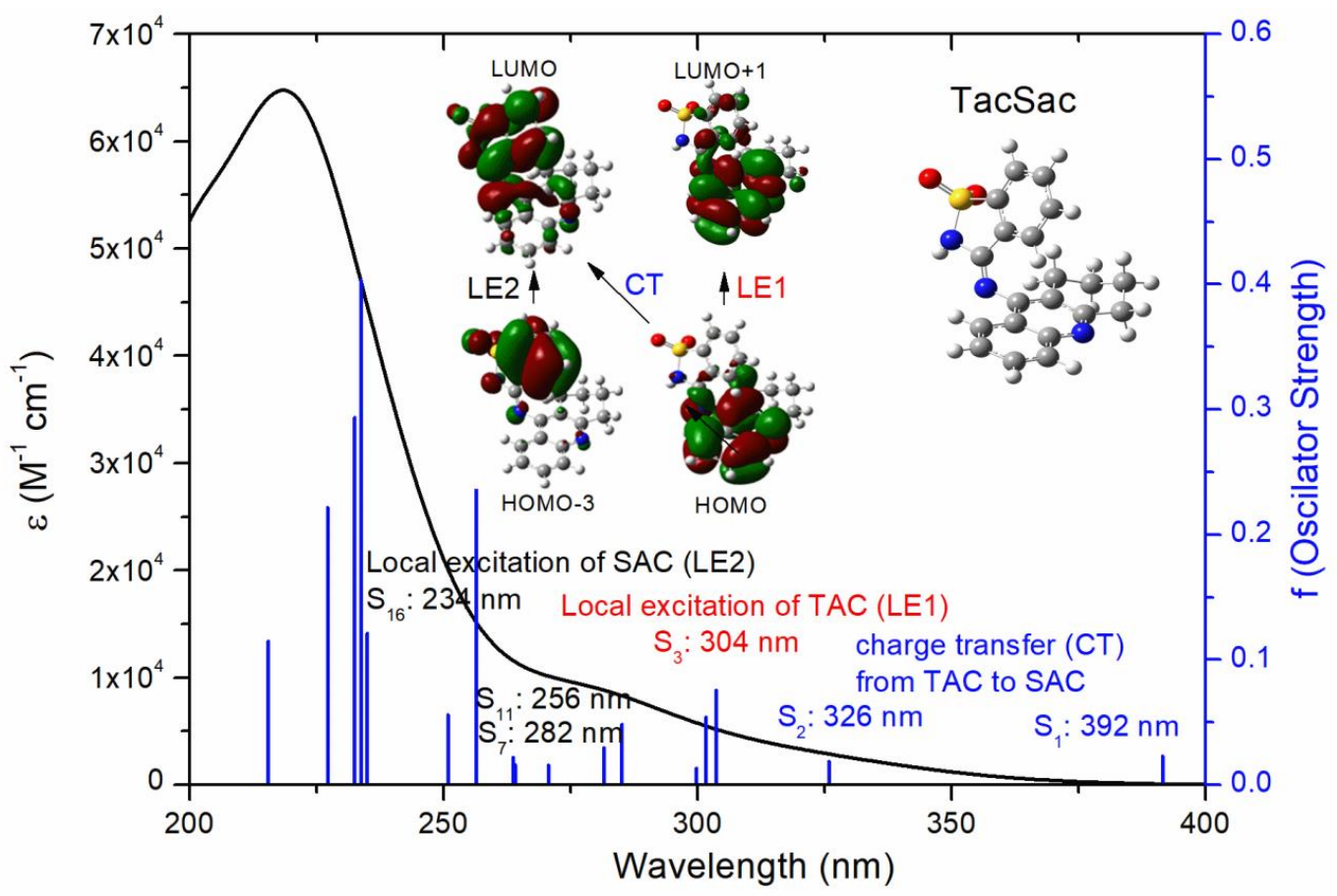

Fig. 5. Calculated UV-Vis spectrum of TacSac in $\mathrm{H}_{2} \mathrm{O}$ at $\mathrm{B} 3 \mathrm{LYP} / 6-311++\mathrm{G}(\mathrm{d}$,p) including all major transitions and corresponding molecular orbitals.

TacSac displays additional characteristics compared to its parent compounds (Fig 4, Table 5). The $\mathrm{S}_{1}$ electronic transition corresponds to a charge transfer from Tac to Sac (CT1) at $392 \mathrm{~nm}$. LE1 of Tac shows itself at $304 \mathrm{~nm}$ with a $8 \mathrm{~nm}$ shift in TacSac. LE2 of Sac appears at $282 \mathrm{~nm}$ but it has a larger oscillator strength at $256 \mathrm{~nm}$. Calculated UV-Vis spectrum of TacSac in $\mathrm{H}_{2} \mathrm{O}$ including electronic transitions, their corresponding molecular orbitals, extinction coefficients, and oscillator strengths is shown in detail in Fig. 5.

\subsection{Charge Analysis}

In order to understand the changes in charge distribution of the systems upon formation of TacSac, charges obtained from Atomic Polar Tensors (APT) approach were calculated (Table 6).

As seen in Table 6, the charges on the atoms increased in solution significantly in all studied systems except $\mathrm{C}_{\mathrm{C}-\mathrm{NH} 2}$ of Tac which is neutral in all media. In all studied systems, the negative charges are located around $\mathrm{N}$ containing moieties. The charges on $\mathrm{S}$ are almost similar in Sac and TacSac as $S$ is not affected from the reaction being far from the reaction site. Along with $\mathrm{S}$ atom, $\mathrm{C}$ atoms bonded to $\mathrm{N}$ containing moieties carry positive charges due to electron distribution caused by these moieties. It is observed that this charge distribution became more significant in a polar solvent medium like $\mathrm{H}_{2} \mathrm{O}$. Charges of all atoms for Tac, Sac and TacSac are tabulated in supplementary information (Tables S2 and S3) and are also given in bar representation (Figs S2-S4).

APT charge analysis reveal that charge of the $\mathrm{N}$ atom in the ring decreases in TacSac compared to Tac (Tac: -0.683 , TacSac:-0.538 in water) which may also reduce the transition dipole moment in electronic transitions. The calculated transition dipole moments for $\mathrm{S}_{1}$ electronic transition of Tac and TacSac are $1.1441 \mathrm{D}$ and $0.2934 \mathrm{D}$, respectively. This observation may explain the first electronic excitation peak $\left(S_{1}\right)$ magnitudes for Tac (strong, $\mathrm{f}=0.115$ ) and TacSac (weak, $\mathrm{f}=0.0228$ ) as seen in Table 3 and Table 5. This transition has charge transfer character for TacSac; thus, it is not observed in the experimental UV-Vis spectrum due to its very small oscillator strength. Another important factor is the presence of highly positively charged $\mathrm{S}$ atom. Although the negative charge on $\mathrm{N}$ atom decreases in TacSac, $\mathrm{S}$ atom keeps its positive charge and may enhance charge transfer from Tac to Sac moiety. 
Table 6. APT atomic charges for selected atoms of Tac, Sac and TacSac calculated in gas phase and in $\mathrm{H}_{2} \mathrm{O}$ at MP2/6-311++G(d,p) level.

\begin{tabular}{ccccc}
\hline Compound & Atom & Gas & $\mathrm{H}_{2} \mathrm{O}$ & $\mathrm{H}_{2} \mathrm{O}(\mathrm{SMD})$ \\
\hline Tacrine & $\mathrm{N}_{\mathrm{NH} 2}$ & -0.654 & -0.984 & -1.093 \\
& $\mathrm{C}_{\mathrm{C}-\mathrm{NH} 2}$ & 0.036 & 0.061 & 0.058 \\
& $\mathrm{~N}$ & -0.460 & -0.683 & -0.747 \\
Saccharin & 1.145 & 1.682 & 1.885 \\
& $\mathrm{C}_{\mathrm{C}=\mathrm{O}}$ & -0.992 & -1.397 & -1.507 \\
& $\mathrm{~N}_{\mathrm{NH}}$ & 2.185 & 3.101 & 3.298 \\
TacSac & $\mathrm{S}$ & 0.408 & 0.598 & 0.611 \\
& $\mathrm{C}_{\mathrm{C}-\mathrm{N}}$ & -0.726 & -1.058 & -1.088 \\
& $\mathrm{~N}_{\mathrm{C}=\mathrm{N}}$ & 0.898 & 1.307 & 1.349 \\
& $\mathrm{C}_{\mathrm{C}=\mathrm{N}}$ & -0.996 & -1.403 & -1.115 \\
& $\mathrm{~N}_{\mathrm{NH}}$ & -0.375 & -0.538 & -0.572 \\
& $\mathrm{~N}$ & 2.177 & 3.168 & 3.330 \\
\hline
\end{tabular}

\section{Conclusion}

MP2/6-311++G(d,p) level was used to investigate structure, UV-Vis spectra and charge distribution of the amidine (TacSac) formed by reaction of tacrine and saccharin. Based on the former data, this level was chosen to shed light on the structural discrepancies observed with DFT. Electronic transitions were determined using CIS and TD-DFT approaches with the same basis set. The calculations were repeated in solution using polarizable continuum model (PCM). SMD (solvation model based on density) approach was also used to observe the effects of nonelectrostatic factors.

Similar geometries for TacSac was obtained in gas phase and in $\mathrm{H}_{2} \mathrm{O}$ both with PCM and SMD models in contrast to DFT results. Since the discrepancy was observed in PCM calculations in DFT, it may be concluded that the electrostatic interactions were overestimated in DFT-PCM calculations causing significant deviations in the geometry.

The results also revealed that the formed amidine is stable and its formation reaction may not be reversible. This conclusion is also significantly different than our former study as DFT results showed that the formation reaction of TacSac between tacrine and saccharin has highly positive complexation energy values and free energy differences.

In addition to calculations at CIS/6$311++\mathrm{G}(\mathrm{d}, \mathrm{p})$ level for excited state properties, TDDFT calculations were performed at B3LYP/6-
$311++\mathrm{G}(\mathrm{d}, \mathrm{p})$ and CAM-B3LYP/6-311++G(d,p) levels. B3LYP results were calculated to agree better to the experimental UV-Vis spectra of Tac and Sac. TacSac has a peak at a higher wavelength enabling $S_{0} \rightarrow S_{1}$ transition to occur with a lower energy. $S_{0} \rightarrow S_{1}$ transition corresponds to full charge transfer (CT1) between the HOMO and LUMO orbitals of TacSac in $\mathrm{H}_{2} \mathrm{O}$ at $392 \mathrm{~nm}$.

The MP2 results indicate that the TacSac system can be easily synthesized with a condensation reaction, and the amidine product is a potential candidate for photochemical charge-transfer systems.

\section{Acknowledgments}

Some of the calculations were performed on TUBITAK-ULAKBIM TRUBA resources.

\section{Appendix A. Supplementary Material}

Supplementary material to this article can be found online at https://doi.org/10.33435/tcandtc.486573.

\section{References}

[1] S. E. Freeman, R. M. Dawson, Tacrine: a pharmacological review, Prog Neurobiol 36 (1991) 257-277.

[2] V. Tumiatti, A. Minarini, M. L. Bolognesi, A. Milelli, M. Rosini, C. Melchiorre, Tacrine derivatives and Alzheimer's disease. Curr Med Chem 17 (2010) 18251838. 
[3] A. Alberti, The chemical and biological properties of acridines. Sci Prog 37 (1949) 418-434.

[4] F. H. Shaw, G. A. Bentley, The pharmacology of some new anticholinesterases, Aust J Exp Biol Med Sci 31 (1953) 573-576.

[5] P. N. Kaul, Enzyme inhibiting action of tetrahydroaminoacridine and its structural fragments, J Pharm Pharmacol 14 (1962) 243-248.

[6] W. K. Summers, L. V. Majovski, G. M. Marsh, K. Tachiki, A. Kling, Oral tetrahydroaminoacridine in long-term treatment of senile dementia, Alzheimer type, N Engl J Med 315 (1986) 1241-1245.

[7] W. K. Summers, Tacrine, and Alzheimer's treatments, J Alzheimers Dis 9 (2006) 439445.

[8] M. Harel, I. Schalk, L. Ehret-Sabatier, F. Bouet, M. Goeldner, C. Hirth, P. H. Axelsen, I. Silman, J. L. Sussman, Quaternary ligand binding to aromatic residues in the active-site gorge of acetylcholinesterase, Proceedings of the National Academy of Sciences USA 90 (1993) 9031-9035.

[9] L. Pishkar, P. R. Jamaat, S. Makarem, Theoretical study of structure spectral properties of tacrine as Alzheimer drug, J Phys Theor Chem IAU Iran 12(1) (2015) 69-75

[10] K. Y. Wong, A. G. Mercader, L. M. Saavedra, B. Honarparvar, G. P. Romanelli, P. R. Duchowicz, QSAR analysis on tacrinerelated acetylcholinesterase inhibitors, Journal of Biomedical Science 21 (2014) 84.

[11] É. C. M. Nascimento, J. B. L. Martins, M. L. dos Santos, R. Gargano, Theoretical study of classical acetylcholinesterase inhibitors, Chemical Physics Letters 458 (2008) 285289.

[12] M. A. R. Matos, M. S. Miranda, V. M. F. Morais, J. F. Liebman, Saccharin: a combined experimental and computational thermochemical investigation of a sweetener and sulfonamide, Molecular Physics 103(2-3) (2005) 221-228.
[13] R. Kant, Sweet proteins-potential replacement for artificial low calorie sweeteners, Nutrition Journal 4 (2004) 5.

[14] M. R. Weihrauch, V. Diehl, H. Bohlen, Artificial sweeteners-are they potentially carcinogenic?, Med Klin (Munich) 96 (2002) 670-675.

[15] R. B. Kanarek, Does sucrose or aspartame cause hyperactivity in children?, Nutr Rev 52 (1994) 173-175.

[16] S. Cohen, What's the truth about the health risks of sugar substitutes such as saccharin and aspartame?, Health News 7(1) (2001) 10.

[17] L. O. Nabors, Saccharin and aspartame: are they safe to consume during pregnancy?, The Journal of Reproductive Medicine 33 (1988) 102.

[18] A. Hagiwara, S. Fukushima, M. Kitaori, M. Shibata, N. Ito, Effects of three sweeteners on rat urinary bladder carcinogenesis initiated by N-butyl-N-(4-hydroxybutyl)nitrosamine, Gann 75 (1984) 763-768.

[19] A. Brizuela, E. Romano, A. Yurquina, S. Locatelli, S. A. Brandan, Experimental and theoretical vibrational investigation on the saccharinate ion in aqueous solution, Spectrochimica Acta A 95 (2012) 399-406.

[20] V. D. Filimonov, E. A. Krasnokutskay, O. K. Poleshchuk, Yu A. Lesina, V. K. Chaikovskii, Electronic structures and reactivities of iodinating agents in the gas phase and in solutions: a density functional study, Russ Chem B+ 55(8) (2006) 13281336.

[21] M. M. Branda, N. J. Castellani, S. H. Tarulli, O. V. Quinzani, E. J. Baran, R. H. Contreras, DFTstudy of electronic structure of saccharin, thiosaccharin, and their respective 1ons: effects of metal coordination on thiosaccharinate electronic structure. International Journal of Quantum Chemistry 89 (2002) 525-534.

[22] M. Remko, Theoretical study of molecular structure and gas phase acidity of some biologically active sulfonamides, The Journal of Physical Chemistry A 107 (2003) $720-725$.

[23] J. Y. Quek, T. P. Davis, A. B. Lowe, Amidine functionality as a stimulus- 
responsive building block, Chemical Society Reviews 42 (2013) 7326-7334.

[24] T. Ishikawa, in Superbases for Organic Synthesis: Guanidines, Amidines, Phosphazenes and Related Organocatalysts, ed. T. Ishikawa, John Wiley \& Sons, Ltd, 2009, pp. 1-6.

[25] T. I. a. T. Kumamoto, in Superbases for Organic Synthesis: Guanidines, Amidines, Phosphazenes and Related Organocatalysts, ed. T. Ishikawa, JohnWiley \& Sons, Ltd, 2009, pp. 49-86.

[26] A. A. Aly, A. M. Nour-El-Din, Functionality of amidines and amidrazones, ARKIVOC I (2008) 153-194.

[27] S. Maddaford, S. C. Annedi, J. Ramnauth, S. Rakhit, Advancements in the development of nitric oxide synthase inhibitors, Annu. Rep. Med. Chem. 44 (2009) 27-50.

[28] C. Maccallini, M. Fantacuzzi, R. Amoroso, Amidine-Based Bioactive Compounds for the Regulation of Arginine Metabolism, Mini Reviews in Medicinal Chemistry 13 (2013) 1305-1310.

[29] R. L. Shriner, F. W. Neumann, The chemistry of the amidines, Chemical Reviews 35 (1944) 351-425.

[30] E. D. Raczyńska, M. Makowski, M. Hallmann, B. Kamińska, Geometric and energetic consequences of prototropy for adenine and its structural model-a review, RSC Advances 5 (2015) 36587-36604.

[31] P. S. Lobanov, D. V. Dar'in, Acetamidines and acetamidoximes containing an electronwithdrawing group at the $\alpha$-carbon atom: their use in the synthesis of nitrogen heterocycles, Chem Heterocycl Compd 49(4) (2013) 507-528.

[32] J. Nowicki, M. Muszyński, J-P. Mikkola, Ionic liquids derived from organosuperbases: en route to superionic liquids, RSC Advances 6 (2016) 9194 9208.

[33] M. N. C. Soeiro, K. Werbovetz, D. W. Boykin, W. D. Wilson, M. Z. Wang, A. Hemphill, Novel amidines and analogues as promising agents against intracellular parasites: a systematic review, Parasitology 140 (2013) 929-951.
[34] R. A. Michelin, P. Sgarbossa, S. Mazzega Sbovata, V. Gandin, C. Marzano, R. Bertani, Chemistry and biological activity of platinum amidine complexes, ChemMedChem 6 (2011) 1172-1183.

[35] V. T. Mathad, P. V. Solanki, V. Pavankumar, S. B. Uppelli, G. G. Sarode, A process for preparation of dabigatran etexilate mesylate and intermediates thereof, PCT Int. Appl. (2015), WO 2015128875 A2 Sep 03, 2015.

[36] J. E. Taylor, S. D. Bull, J. M. J. Williams, Amidines, isothioureas, and guanidines as nucleophilic catalysts, Chemical Society Reviews 41 (2012) 2109-2121.

[37] J. W. Liebeschuetz, R. B. Katz, A. D. Duriatti, M. L. Arnold, Rationally designed guanidine and amidine fungicides, Pestic Sci 50 (1997) 258-274.

[38] G. Wulff, R. Schönfeld, Polymerizable amidines - adhesion mediators and binding sites for molecular imprinting, Adv Mater 10(12) (1998) 957-959.

[39] S. Erol Gunal, G. Sabuncu Gurses, S. Sag Erdem, I. Dogan. Synthesis of stable tetrahedral intermediates (hemiaminals) and kinetics of their conversion to thiazol-2imines, Tetrahedron 72 (2016) 2122-2131.

[40] G. Kantin, M. Krasavin, N-arylation of amidines and guanidines: an update, Current Organic Chemistry 20(13) (2016) 13701388.

[41] N. Acar, C. Selçuki, E. Coşkun, DFT and TDDFT investigation of the Schiff base formed by tacrine and saccharin, Journal of Molecular Modeling 23 (2017) 17.

[42] R. D. Dennington II, T. A. Keith, J. M. Millam, GaussView 5.0.9, Wallingford, CT, (2009)

[43] M. J. Frisch, G. W. Trucks, H. B. Schlegel, G. E. Scuseria, M. A. Robb, J. R. Cheeseman, G. Scalmani, V. Barone, B. Mennucci, G. A. Petersson, H. Nakatsuji, M. Caricato, X. Li, H. P. Hratchian, A. F. Izmaylov, J. Bloino, G. Zheng, J. L. Sonnenberg, M. Hada, M. Ehara, K. Toyota, R. Fukuda, J. Hasegawa, M. Ishida, T. Nakajima, Y. Honda, O. Kitao, H. Nakai, T. Vreven, J. A. Montgomery Jr., J. E. Peralta, F. Ogliaro, M. Bearpark, J. J. Heyd, E. 
Brothers, K. N. Kudin, V. N. Staroverov, R. Kobayashi, J. Normand, K. Raghavachari, A. Rendell, J. C. Burant, S. S. Iyengar, J. Tomasi, M. Cossi, N. Rega, J. M. Millam, M. Klene, J. E. Knox, J. B. Cross, V. Bakken, C. Adamo, J. Jaramillo, R. Gomperts, R. E. Stratmann, O. Yazyev, A. J. Austin, R. Cammi, C. Pomelli, J. W. Ochterski, R. L. Martin, K. Morokuma, V. G. Zakrzewski, G. A. Voth, P. Salvador, J. J. Dannenberg, S. Dapprich, A. D. Daniels, Ö. Farkas, J. B. Foresman, J. V. Ortiz, J. Cioslowski, D. J. Fox, Gaussian 09, Revision C.01, Gaussian, Inc., Wallingford CT (2009).

[44] M. J. Frisch, M. Head-Gordon, J. A. Pople, A direct MP2 gradient method, Chemical Physics Letters 166 (1990) 275-280.

[45] M. Head-Gordon, J. A. Pople, M. J. Frisch, MP2 energy evaluation by direct methods, Chemical Physics Letters 153 (1988) 503506.

[46] W. J. Hehre, L. Radom, P. V. Schleyer, J. A. Pople, Ab Initio Molecular Orbital Theory, John Wiley \& Sons, New York, USA, 1986, 576.

[47] J. B. Foresman, M. Head-Gordon, J. A. Pople, and M. J. Frisch, Toward a Systematic Molecular Orbital Theory for Excited States, The Journal of Physical Chemistry 96 (1992) 135-149.

[48] A. D. Becke, Density-functional thermochemistry. III. The role of exact exchange, The Journal of Chemical Physics 98 (1993) 5648-5652.

[49] C. Lee, W. Yang, R. G. Parr, Development of the Colle-Salvetti correlation-energy formula into a functional of the electron density, Physical Review B 37 (1988) 785789.

[50] T. Yanai, D. Tew, N. Handy, A new hybrid exchange-correlation functional using the Coulomb-attenuating method (CAMB3LYP), Chemical Physics Letters 393 (2004) 51-57.

[51] J. Tomasi, B. Mennucci, E. Cancès, The IEF version of the PCM solvation method: an overview of a new method addressed to study molecular solutes at the QM ab initio level, Journal of Molecular Structure THEOCHEM 464 (1999) 211-226.

[52] J. Tomasi, B. Mennucci, R. Cammi, Quantum mechanical continuum solvation models, Chemical Reviews 105 (2005) 2999-3093.

[53] A. V. Marenich, C. J. Cramer, D. G. Truhlar, Universal solvation model based on solute electron density and on a continuum model of the solvent defined by the bulk dielectric constant and atomic surface tensions, The Journal of Physical Chemistry B 113 (2009) 6378-6396.

[54] J. Cioslowski, A new population analysis based on atomic polar tensors, Journal of American Chemical Society 111(22) (1989) 8333-8336. 